\title{
PENGARUH VARIASI MATERIAL ALUMUNIUM TERHADAP UNJUK KERJA NANOGENERATOR PIEZOELEKTRIK DENGAN MATERIAL SENG OKSIDA
}

\author{
Lukman Nulhakim \\ Program Studi Teknik Mesin \\ Politeknik Enjinering Indorama \\ Email: lukman.mesin@gmail.com
}

\begin{abstract}
ABSTRAK
Teknologi mengubah energi mekanik menjadi energi listrik disebut piezoelektrik. Dimana material yang digunakan mempunyai bentuk kristal non-sentrosimetris dengan ukuran nano berbentuk serat. Metode yang digunakan yaitu metode elektrospining, dimana membuat serat dengan ukuran nano dengan menggunakan tegangan sebesar $15 \mathrm{kV}$ dengan laju aliran $2 \mu \mathrm{l} / \mathrm{m}$. Penelitian ini menggunakan variasi 3, 5 dan $7 \% \mathrm{Al}$ dari berat total $\mathrm{ZnAc}-\mathrm{AlCl}_{3}$. Variasi penambahan $\mathrm{Al}$ terhadap $\mathrm{ZnO}$ dapat mempengaruhi ukuran serat serta daya dan tegangan yang dihasilkan nanogenerator piezoelektrik. Ukuran serat yang dihasilkan hingga $84 \mathrm{~nm}$ pada penambahan $7 \%$ Al serta tegangan dan daya terbesar yaitu sebesar 122,89 $\mathrm{mV}$ dan $93,65 \mathrm{nW}$ pada $7 \% \mathrm{Al}$.
\end{abstract}

Kata kunci: nanogenerator, elektrospinning, $\mathrm{ZnO}$, aluminium, piezoelektrik.

\begin{abstract}
Technology converts mechanical energy into electrical energy is piezoelectric. Where the material used has a non - crystalline form centrosymetris with the size of nano-shaped fibers. The method used is the method of electrospinning, which create a letter with the nano-size by using a voltage of $15 \mathrm{kV}$ with a flow rate of $2 \mu \mathrm{l} / \mathrm{m}$. This study used several variations of 3, 5 and $7 \% \mathrm{Al}$ of the total weight $\mathrm{ZnAc}-$ $\mathrm{AlCl}_{3}$. Variations addition of $\mathrm{Al}$ to $\mathrm{ZnO}$ can affect the size of the fiber as well as power and voltage produced by the piezoelectric nanogenerator. The resulting fiber size up to $84 \mathrm{~nm}$ on the addition of $7 \%$ $\mathrm{Al}$, and the voltage and the greatest power in the amount of $122,89 \mathrm{mV}$ and $93,65 \mathrm{nW} / \mathrm{cm}^{2}$ at $7 \% \mathrm{Al}$.
\end{abstract}

Keywords: nanogenerator, electrospinning, $\mathrm{ZnO}$, aluminium, piezoelectric.

\section{PENDAHULUAN}

Efek piezoelektrik dimanfaatkan untuk mengubah energi mekanik menjadi energi listrik dengan memberi beban pada suatu material tertentu yang mempunyai bentuk kristal non-sentrosimetris [1]. ZnO merupakan material dasar yang menarik untuk diteliti, karena material tersebut mempunyai bentuk kristal non-sentrosimetris sehingga dapat digunakan sebagai material piezoelektrik.

Elektrospinning merupakan metode untuk membuat material piezoelektrik berbasis serat nano, dimana biaya yang dibutuhkan dengan metode ini cukup terjangkau [2]. Ukuran serat yang dihasilkan dalam proses elektrospinning lebih besar dikarenakan pengaruh dari laju aliran prekursor yang lebih besar.

Penelitian dilakukan tentang penggunaan material $\mathrm{ZnO}$ berbasis nanowire sebagai nanogenerator telah menghasilkan tegangan sampai $25 \mathrm{mV}$ [3]. Penelitian lain tentang material $\mathrm{ZnO}$ yang didoping dengan Aluminium (Al) berbasis nanorods dapat menghasilkan tegangan hingga $60 \mathrm{mV} \mathrm{[4].}$

Penelitian ini akan mempelajari metode perbaikan unjuk kerja nanogenerator $\mathrm{ZnO}$ dengan penambahan material lain (dopant), yaitu alumunium (Al) yang berasal dari material $\mathrm{AlCl}_{3}$. Pemilihan material Al karena dapat memperkecil serat $\mathrm{ZnO}$ [5]. Maka menarik untuk dilakukan penelitian tentang penambahan material Al sebagai doping dengan material $\mathrm{ZnO}$ sehingga hasil yang diharapkan ukuran serat mengecil dan unjuk kerja dari material piezoelektrik meningkat.

\section{METODOLOGI PENELITIAN}

Proses pengadukan serbuk PVA dicampur dengan $\mathrm{H}_{2} \mathrm{O}(1: 10 \% \mathrm{wt})$ pada temperatur $70{ }^{\circ} \mathrm{C}$ selama 4 jam dan didiamkan pada temperatur ruang selama 8 jam. Kemudian larutan $\mathrm{ZnAc}: \mathrm{AlCl}_{3}(1: 5 \%$ wt) diperoleh dengan variasi penambahan campuran $\mathrm{AlCl}_{3}$ sebesar 3, 5 dan $7 \%$, dari berat total yaitu masingmasing $4 \mathrm{~g}$ pada $20 \mathrm{~g} \mathrm{H}_{2} \mathrm{O}$ yang diaduk dengan temperatur $70{ }^{\circ} \mathrm{C}$ selama $1 \mathrm{jam}$. Setelah itu larutan 
ZnAc: $\mathrm{AlCl}_{3}$ masing-masing dicampur dengan larutan PVA (1:4\%wt) dan diaduk pada temperatur $70{ }^{\circ} \mathrm{C}$ selama 8 jam, didiamkan pada temperatur ruang selama 24 jam, sehingga dihasilkan 3 larutan bening $\mathrm{ZnAc}: \mathrm{AlCl}_{3}$ :PVA yang disiapkan untuk mensintesa serat nano.

Pelat

kolektor

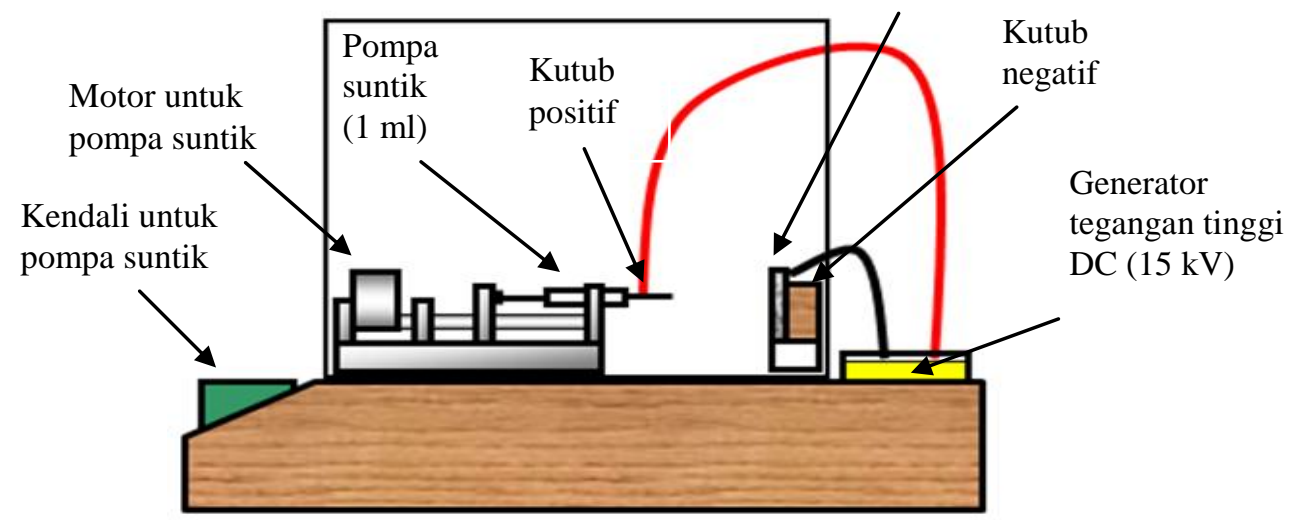

Gambar 1. Mesin elektrospinning horisontal [6]

Larutan bening $\mathrm{ZnAc:} \mathrm{AlCl}_{3}$ :PVA dimasukkan ke dalam $1 \mathrm{ml}$ pompa suntik untuk menghasilkan sintesa serat nano dengan menggunakan mesin elektrospinning (Gambar 1). Jarum dihubungkan dengan terminal positif dengan jarak $8 \mathrm{~cm}$ horisontal terhadap pelat kolektor aluminium yang terhubung dengan terminal negatif, sedangkan tegangan tinggi DC yang digunakan sebesar $15 \mathrm{kV}$.

Pada saat tegangan tinggi dihidupkan dan larutan yang ada didalam pompa suntik mulai didorong keluar dengan laju aliran $2 \mu \mathrm{l} /$ menit, larutan akan tertarik oleh medan elektrostatis dan menempel dengan sendirinya pada permukaan pelat kolektor aluminium dengan ukuran $6 \times 6 \mathrm{~cm}$ menjadi green fibers. Selanjutnya untuk menghilangkan materi organik seperti PVA dilakukan sintering dengan temperatur 500 ${ }^{\circ} \mathrm{C}$ selama 4 jam, karena PVA diatas temperatur $440{ }^{\circ} \mathrm{C}$ sudah terdekomposisi seluruhnya dan yang tersisa hanyalah serat nano [7].

Kemampuan unjuk kerja piezoelektrik untuk menghasilkan energi listrik diukur dengan membaca perubahan tegangan secara langsung (realtime) dengan penerapan beban tekan-lepas sebesar 0,5 kgf. Peralatan yang digunakan adalah akuisisi data merek ADAM Advantech seri 4018. Pemilihan beban 0,5 kgf dilakukan untuk mewakili kondisi terapan tekanan jari lemah [8].

Unjuk kerja piezoelektrik dapat dicari berdasarkan besarnya daya (Watt) yang dihasilkan dengan memberikan variasi beban tahanan $(\Omega)$. Peralatan untuk mengakuisisi data perubahan tegangan (Volt) yang dihasilkan oleh masing-masing nanogenerator piezoelektrik $\mathrm{ZnO}$ doping $\mathrm{Al}$ (Al-ZnO), selain itu juga dilakukan pengujian karakterisasi morfologi serat nano diperoleh dengan pengujian SEM.

\section{HASIL DAN PEMBAHASAN}

\subsection{Pengujian SEM}

Pengujian SEM untuk material $\mathrm{ZnO}$ doping Al dilakukan pada pembesaran 50.000 X. Foto SEM material $\mathrm{ZnO}$ yang didoping $\mathrm{Al}$ terlihat pada Gambar 2, dimana semakin besar doping Al semakin mengecil serat nano yang dihasilkan.

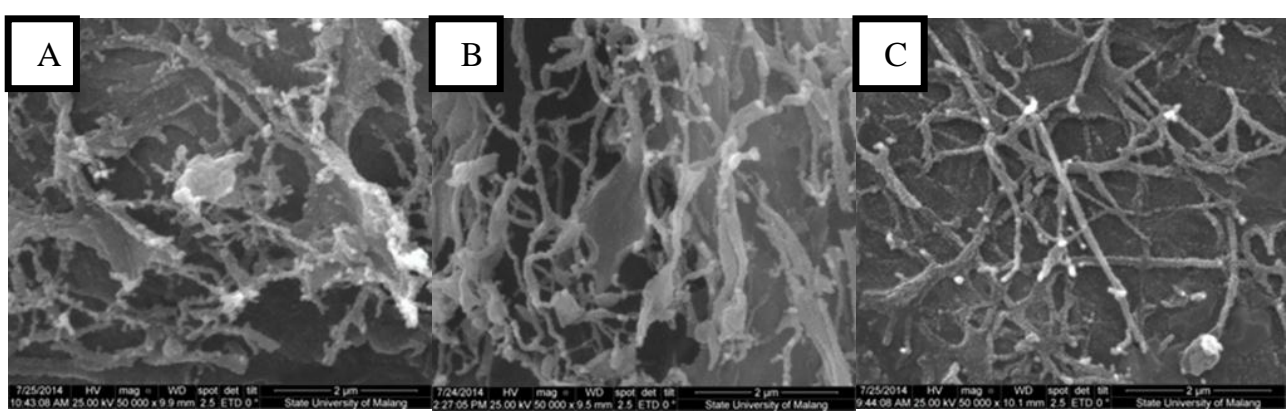

Gambar 2. a). Foto SEM ZnO dengan $3 \%$ Al; b). Foto SEM ZnO dengan $5 \%$ Al; dan c). Foto SEM ZnO dengan $7 \%$ Al. 
Diameter serat dari $\mathrm{ZnO}$ doping $\mathrm{Al}$ yang dihasilkan disajikan pada tabel 1. Semakin besar jumlah doping Al semakin kecil serat yang dihasilkan dan serat yang terbentuk beberapa masih saling bergabung. Ukuran serat $\mathrm{ZnO}$ yang dihasilkan pada saat pendopingan Al antara 84-105 nm. Hal ini disebabkan pada saat proses elektrospinning, larutan yang mengandung $\mathrm{AlCl}_{3}$ mempunyai konduktivitas listrik yang lebih tinggi. Gelembung larutan dengan konduktivitas listrik tinggi yang keluar dari syringe pump lebih mudah ditarik oleh medan elektrostatik, sehingga ukuran dari serat yang dihasilkan lebih kecil.

Tabel 1. Diameter serat nano $\mathrm{ZnO}$ dengan pendopingan $\mathrm{Al}$

\begin{tabular}{llccc}
\hline \multirow{2}{*}{ Jenis Doping } & \multirow{3}{*}{ Diameter serat } & \multicolumn{3}{c}{ Rasio jumlah } \\
\cline { 2 - 5 } & & $\mathbf{3}$ & $\mathbf{5}$ & $\mathbf{7}$ \\
\hline \multirow{3}{*}{$\mathrm{AlCl}_{3}$} & Maksimum (nm) & 141 & 137 & 130 \\
& Minimum (nm) & 65 & 55 & 52 \\
& Rata-rata (nm) & 105 & 86 & 84 \\
\hline
\end{tabular}

\subsection{Pengujian Unjuk Kerja Nanogenerator Piezoelektrik}

Pengujian unjuk kerja nanogenerator dilakukan dengan penerapan beban tekan-lepas sebesar 0,5 kg setiap 3 detik per siklus. Pengujian dilakukan dengan pengamatan terhadap perubahan tegangan keluaran $(\mathrm{mV})$ dan daya keluaran $(\mathrm{nW})$ dengan beberapa variasi hambatan $(\mathrm{M} \Omega)$. Grafik hasil pengujian unjuk kerja nanogenerator piezoelektrik berbasis Al-ZnO disajikan pada gambar 3 dan gambar 4. Besarnya daya dan tegangan maksimum yang dihasilkan nanogenerator piezoelektrik berbasis $\mathrm{Al}-\mathrm{ZnO}$ dapat dilihat pada tabel 2 dan tabel 3 .

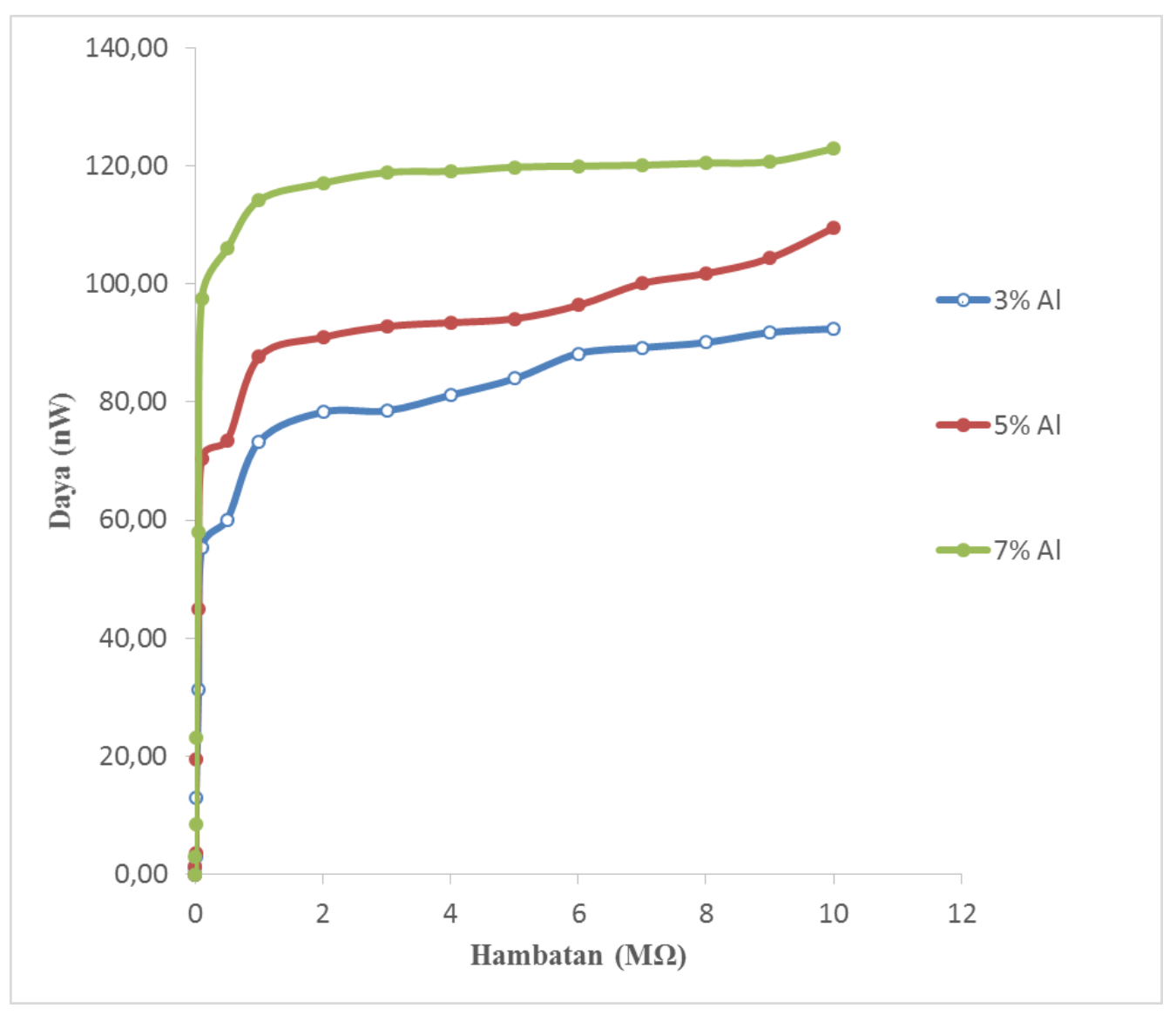

Gambar 3. Grafik tegangan dari nanogenerator piezoelektrik Al-ZnO 


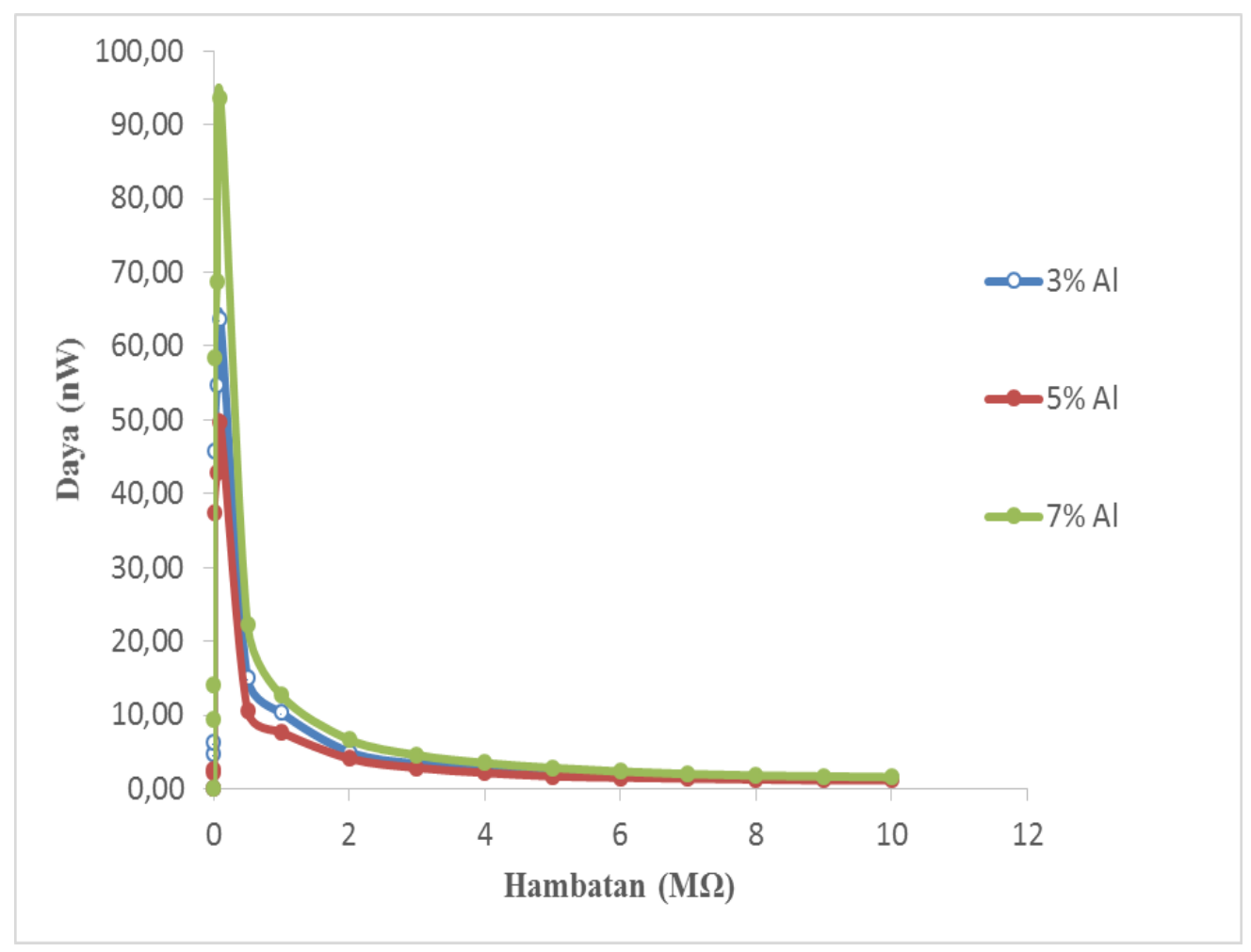

Gambar 4. Grafik daya dari nanogenerator piezoelektrik Al-ZnO

Tabel 2. Tegangan hasil pada nanogenerator piezoelektrik Al-ZnO

\begin{tabular}{lcccc}
\hline \multirow{2}{*}{$\begin{array}{c}\text { Pengukuran } \\
\text { Unjuk Kerja }\end{array}$} & Hambatan & \multicolumn{3}{c}{ Doping (\%) } \\
\cline { 3 - 5 } & $\mathbf{M} \boldsymbol{\Omega})$ & $\mathbf{3}$ & $\mathbf{5}$ & $\mathbf{7}$ \\
\hline & $\mathbf{0}$ & 0,00 & 0,00 & 0,00 \\
& $\mathbf{0 , 0 0 1}$ & 1,22 & 1,33 & 2,89 \\
& $\mathbf{0 , 0 0 5}$ & 2,98 & 3,66 & 8,46 \\
& $\mathbf{0 , 0 1}$ & 12,98 & 19,42 & 23,11 \\
& $\mathbf{0 , 0 5}$ & 31,20 & 44,96 & 57,96 \\
& $\mathbf{0 , 1}$ & 55,28 & 70,49 & 97,54 \\
& $\mathbf{0 , 5}$ & 60,09 & 73,45 & 105,94 \\
Tegangan & $\mathbf{1}$ & 73,30 & 87,63 & 114,17 \\
$(\mathbf{m V )}$ & $\mathbf{2}$ & 78,28 & 90,94 & 117,07 \\
& $\mathbf{3}$ & 78,50 & 92,79 & 118,87 \\
& $\mathbf{4}$ & 81,15 & 93,42 & 119,04 \\
& $\mathbf{5}$ & 83,93 & 94,08 & 119,77 \\
& $\mathbf{6}$ & 88,20 & 96,35 & 119,93 \\
& $\mathbf{7}$ & 89,20 & 100,06 & 120,09 \\
& $\mathbf{8}$ & 90,07 & 101,74 & 120,43 \\
& $\mathbf{9}$ & 91,76 & 104,33 & 120,65 \\
& $\mathbf{1 0}$ & 92,39 & 109,47 & 122,89 \\
\hline
\end{tabular}


Tabel 3. Daya hasil pada nanogenerator piezoelektrik Al-ZnO

\begin{tabular}{|c|c|c|c|c|}
\hline \multirow{2}{*}{$\begin{array}{l}\text { Pengukuran } \\
\text { Unjuk Kerja }\end{array}$} & \multirow{2}{*}{$\begin{array}{c}\text { Hambatan } \\
(M \Omega)\end{array}$} & \multicolumn{3}{|c|}{ Doping (\%) } \\
\hline & & 3 & 5 & 7 \\
\hline \multirow{17}{*}{ Daya (nW) } & 0 & 0,00 & 0,00 & 0,00 \\
\hline & 0,001 & 2,15 & 4,67 & 9,43 \\
\hline & 0,005 & 2,72 & 6,40 & 14,15 \\
\hline & $\mathbf{0 , 0 1}$ & 37,35 & 45,81 & 58,40 \\
\hline & 0,05 & 42,93 & 54,70 & 68,73 \\
\hline & 0,1 & 49,65 & 63,71 & 93,65 \\
\hline & 0,5 & 10,64 & 15,02 & 22,30 \\
\hline & 1 & 7,69 & 10,32 & 12,67 \\
\hline & 2 & 4,12 & 5,00 & 6,69 \\
\hline & 3 & 2,86 & 3,40 & 4,58 \\
\hline & 4 & 2,19 & 3,03 & 3,51 \\
\hline & 5 & 1,71 & 2,02 & 2,84 \\
\hline & 6 & 1,53 & 2,01 & 2,36 \\
\hline & 7 & 1,42 & 1,87 & 2,01 \\
\hline & 8 & 1,29 & 1,60 & 1,80 \\
\hline & 9 & 1,18 & 1,42 & 1,70 \\
\hline & 10 & 1,17 & 1,43 & 1,60 \\
\hline
\end{tabular}

Material piezo adalah material yang jika diberi beban dapat mengeluarkan listrik. Pada saat pembebanan kontinu sebesar $0,5 \mathrm{~kg}$, tegangan yang dikeluarkan oleh serat Al-ZnO tergantung dari beban tahanan yang diberikan. Pada pembebanan $0 \mathrm{M} \Omega$ sampai $1 \mathrm{M} \Omega$ terjadi peningkatan tegangan dan daya, tetapi setelah $1 \mathrm{M} \Omega$ besarnya tegangan yang dihasilkan oleh masing-masing nanogenerator hanya mengalami peningkatan yang kecil atau hampir dikatakan stabil. Daya yang dihasilkan setelah pembebanan $1 \mathrm{M} \Omega$ terjadi penurunan yang sangat signifikan.

Pada doping $7 \%$ Al, tegangan yang dihasilkan meningkat dibandingkan yang dihasilkan oleh nanogenerator $\mathrm{ZnO}$ dengan doping 3 dan $5 \%$ Al. Tegangan keluaran maksimum dari nanogenerator piezoelektrik berbasis $\mathrm{ZnO}$ yang didoping $7 \% \mathrm{Al}$ adalah 122,89 $\mathrm{mV}$. Dibanding dengan penelitian sebelumnya yang menggunakan piezoelektrik dengan lapisan tipis $\mathrm{ZnO}$ mampu menghasilkan tegangan kurang dari $20 \mathrm{mV}$ pada pembebanan kurang dari 0,4 kg dan kurang dari $60 \mathrm{mV}$ pada pembebanan antara $0,4 \mathrm{~kg}$ sampai $1 \mathrm{~kg}$ [8]. Nilai daya keluaran maksimum dari nanogenerator berbasis $\mathrm{ZnO}$ yang di doping dengan $7 \%$ Al juga meningkat sampai 93,65 nW/ $\mathrm{cm}^{2}$. Hasil ini masih lebih tinggi dibandingkan dengan hasil penelitian sebelumnya, yaitu $38.8 \mathrm{nW} / \mathrm{cm}^{2}[6]$.

\section{KESIMPULAN}

Nanogenerator piezoelektrik doping $7 \% \mathrm{Al}$ pada $\mathrm{ZnO}$ mampu meningkatkan daya sebesar 93,65 $\mathrm{nW}$ dan tegangan sebesar 122,89 mV. Selain itu dengan adanya doping Al pada ZnO dapat memperkecil serat nano hingga $84 \mathrm{~nm}$, dimana semakin besar doping Al menyebabkan serat nano semakin kecil serta daya dan tegangan yang dihasilkan semakin besar.

\section{DAFTAR PUSTAKA}

[1] Haertling, G.H., 1999, Ferroelectric Ceramics: History and Technology, pp. 797-818.

[2] He, J.-H., Liu, Y., Mo, L.-F., Wan, Y.-Q., and Xu, L., 2008, Electrospun Nanofibres and Their Applications.

[3] Wang, Z.L., Wang, X., Song, J., Liu, J., and Gao, Y., 2008, Piezoelectric Nanogenerators for SelfPowered Nanodevices, Vol 7.

[4] Fang, T.-H., and Kang, S.-H., 2010, Physical Properties of ZnO:Al Nanorods for Piezoelectric Nanogenerator Application, Current Nanoscience, Vol. 6, pp 1-7. 
[5] Lee, D.Y., Cho, J.E., Cho, N.I., Lee, M.H., Lee, S.J., and Kim, B.Y., 2008, Characterization of Electrospun Aluminium-Doped Zinc Oxide Nanofibers, Thin Solid Film, Vol. 517 pp. 1262-1267.

[6] Sholahuddin, I., 2013, Fabrikasi Nanogenerator Zno Dan AZO Berbasis Serat Nano Dengan Metode Elektrospinning.

[7] Yang, X., Shao, C., Guan, H., Li, X., and Gong, J., 2004, Preparation and Characterization of ZnO Nanofibers by Using Electrospun PVA/Zinc Acetate Composite Fiber as Precursor, Inorganic Chemistry Communications, Vol. 7 pp. 176-178.

[8] Choi, D., Lee, K.Y., Lee, K.H., Kim, E.S., Kim, T.S., Lee, S.Y., et al., 2010, Piezoelectric TouchSensitive Flexible Hybrid Energy Harvesting Nanoarchitectures, Nanotechnology, Vol. 21 (40), pp. 405503. 